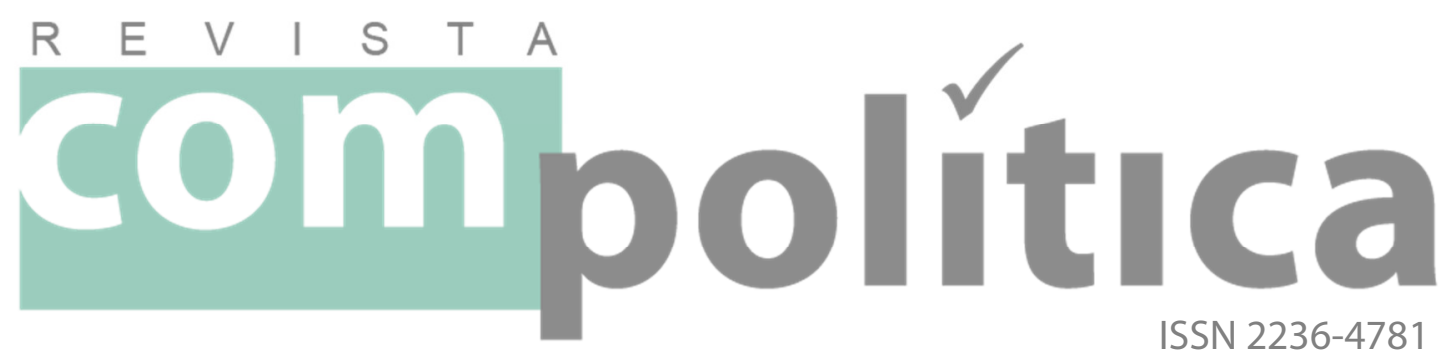

Democracia desconectada: da necessidade do diálogo com a literatura nacional

[Disconnected democracy: on the necessity for dialogue with the national literature]

\author{
SAMPAIO, Rafael Cardoso \\ Doutor em Comunicação e Cultura pela UFBA. \\ Professor da UFPR \\ [PhD on Communication and Culture from Bahia \\ Federal University. Professor at Paraná Federal \\ University] \\ <cardososampaio@gmail.com>
}

RESENHA DE

MAGRANI, Eduardo. Democracia conectada: a internet como ferramenta de engajamento políticodemocrático. Curitiba: Juruá/FGV Direito Rio, 2014
BOOK REVIEW

MAGRANI, Eduardo. Democracia conectada: a internet como ferramenta de engajamento políticodemocrático. Curitiba: Juruá/FGV Direito Rio, 2014. 


\section{Democracia desconectada: da necessidade do diálogo com a literatura nacional}

SAMPAIO, Rafael Cardoso

Este texto pretende apresentar uma resenha crítica sobre o
livro "Democracia conectada: A Internet como Ferramenta de Engajamento Político-Democrático", de Eduardo Magrani, publicado pela editora Juruá com apoio da Escola de Direito da Fundação Getulio Vargas no Rio de Janeiro (FGV-Direito/Rio). Trata-se de um livro voltado a discutir, essencialmente, conceitos, fenômenos, potenciais e questões dentro do guarda-chuva teórico da democracia digital. Ao que tudo indica, o livro é uma adaptação da dissertação de mestrado do autor, intitulada "A esfera pública conectada: a Internet como ferramenta de engajamento político-democrático", defendida no Programa de Pós-Graduação em Direito da PUC-Rio e disponível online ${ }^{1}$. O livro, por sinal, também está disponível em um dispositivo online de leitura da editora (não é possível baixá-lo, mas é possível acessá-lo ${ }^{2}$ ). 0 processo de edição não foi o suficiente para esconder as marcas de um trabalho de conclusão de curso acadêmico. Então, o leitor chegará ao terceiro nível de uma subseção ("2.1.6") de forma idêntica ao apresentado em sua dissertação. Ainda, as notas de rodapé frequentemente fazem alusões a URLs e links excessivamente extensos para o leitor se animar a digitá-los manualmente; erros que atribuo aos editores do livro e não, necessariamente, ao autor.

Pretendo apresentar, detalhadamente, pontos fortes e fracos da obra, esmiuçando seus capítulos, porém é possível já adiantar ao

\footnotetext{
${ }^{1}$ http://www2.dbd.puc-rio.br/pergamum/tesesabertas/1213305_2014_completo. pdf. Acesso em 28 Out. 2015.

${ }^{2}$ https://www.jurua.com.br/bv/conteudo.asp?id=23590.
} 
leitor a conclusão desta resenha. Trata-se de um livro bem escrito, que aborda inúmeros temas, problemas, fenômenos e questões relevantes à democracia digital e que, certamente, poderá ser útil aos alunos ou pesquisadores novatos na área. Não obstante, trata-se, também, de uma obra que pouco tem a contribuir para a pesquisa mais avançada em democracia digital no Brasil. Em especial, é preciso destacar que o autor não dialoga em absoluto com a literatura brasileira acerca do tema. 0 perigo na indicação ao leigo é justamente a impressão de que Magrani é o precursor do conceito no Brasil e que suas visões sobre certas teorias são as vigentes e não pessoais, como, de fato, são. A esta conclusão retornarei na parte final de minha resenha.

\section{As diferentes visões da democracia conectada}

O primeiro capítulo, "A esfera pública conectada: de Habermas a Benkler", busca apresentar a origem do conceito de "esfera pública", tendo a obra de Jürgen Habermas como referência, e atualizações ao conceito, especialmente na definição de "esfera pública conectada" de Yonchai Benkler (2006). Todavia, é possível se verificar que, na prática, o capítulo tenderá a tratar de questões, fenômenos e discussões muito distintas entre si.

A parte inicial do capítulo é, definitivamente, interessante. Magrani é capaz de explicar com habilidade os complexos conceitos de Habermas, dando ênfase a questões do Direito, da Comunicação e mesmo aos aspectos sociológicos e democráticos da obra Habermasiana. $O$ autor chega a apresentar algumas definições e atualizações do conceito para o contexto da América Latina através dos escritos de Sérgio Costa (2002). Particularmente, senti falta das 
críticas e atualizações ao conceito ${ }^{3}$. No caso brasileiro, não há referências ao livro de Gomes \& Maia (2008), que discute e atualiza o conceito em vários aspectos. Também não há referências às novas atualizações da discussão acerca da democracia deliberativa, como é o caso, por exemplo, do conceito de sistema deliberativo (MAIA, 2012; PARKINSON, MANSBRIDGE, 2012) ou como considerar na deliberação outras formas menos exigentes de comunicação, como sentimentos, humor, narrativas e testemunhos (e.g. STEINER, 2012). Em vez disso, o autor faz uma escolha não justificada por apresentar o clássico orçamento participativo (OP) como exemplo prático de uma política mais deliberativa. Os leitores, certamente, tenderão a estranhar esta seção, já que ela se encontra perdida e pouco é, efetivamente, conectada ao objetivo geral do capítulo ou mesmo do livro. $\mathrm{O}$ autor começa a apresentar um conjunto de dados sobre a origem e expansão do OP pelo mundo, que pouco ajudam em seu objetivo - afinal o OP surge apenas de forma marginal para, supostamente, exemplificar uma aplicação de democracia deliberativa. Magrani ainda tenta fazer a conexão através da ideia de orçamento participativo digital, porém acaba abordando-o de forma apenas ilustrativa e desconectada da discussão final do livro. Destaco que mesmo já existindo uma produção interessante sobre o OP Digital de Belo Horizonte, que inclui um conjunto de dissertações, teses, artigos e capítulos (ABREU, 2012; BEST et al., 2010; FERREIRA, 2012; SAMPAIO, 2010), o autor não dialoga com a produção existente.

A partir deste momento, Magrani trata sobre a ideia de esfera pública conectada de Benkler (2006), usando de forma complementar os escritos a respeito de redes de Castells $(1999,2007)$. De forma resumida, Magrani faz um bom trabalho na apresentação das teorias dos autores, apesar de ser notável como não tenta dialogar ou se

\footnotetext{
3 Inclusive, o próprio Habermas (2008) faz atualizações às suas ponderações anteriores.
} 
contrapor a seus fundamentos (o que só virá no capítulo 2). Trata-se da apresentação da literatura otimista sobre esfera pública online, engajamento, sociedade da informação etc. Ao fim, o autor vai apresentar o conceito de e-democracia (p. 64) e reconhece, de modo correto, que se trata da possibilidade do avanço de diversos valores democráticos pelos usos e apropriações de tecnologias de comunicação e informação. $O$ autor também reconhece que há fenômenos e iniciativas de cima para baixo ou top-down (que o autor denomina como "institucionais") e de baixo para cima ou bottom-up (“não institucionais"). Porém, na prática, o autor falha em apresentar e delinear a diferença entre os dois vértices da democracia digital. Em vez de, efetivamente, discutir os conceitos e questões relacionadas, ele opta por ilustrar cada vértice com um exemplo. No caso, o Transparência Brasil ${ }^{4}$, no vértice nãoinstitucional, e o e-Democracia da Câmara dos Deputados ${ }^{5}$, no vértice institucional. Ambos os projetos são apresentados, mas sem muito vigor ou discussão, geralmente permanecendo no nível ilustrativo. Aqui, por exemplo, dialogar com as definições de Gomes (2010), ao nível nacional, e Coleman \& Blumler (2009), em perspectiva mundial, teria sido profícuo para a melhor diferenciação entre as duas direções da democracia digital. Não há, também, referências aos diversos estudos e reflexões sobre e-democracia institucional (BRAGA, 2007; BRAGATTO, 2011; CUNHA, 2009; GOMES, 2005, 2010, 2011; MARQUES, 2010; SILVA, 2005; ROTHBERG, 2008), sobre Webcidadania (DINIZ, RIBEIRO, 2012; MAIA, 2007; PENTEADO, SANTOS, ARAÚJO, 2011; ROSSETTO, CARREIRO, 2012; SILVEIRA, 2009), sobre o valor da informação (BEZERRA, 2008) e sobre transparência no Brasil (ALMADA, 2013; AMORIM, 2012; PINHO, 2008; PRADO, 2004) ou mesmo sobre o projeto e-democracia em si (FARIA,

\footnotetext{
${ }^{4}$ http://www.transparencia.org.br/. Acesso em 12 nov. 2015.

${ }^{5}$ http://edemocracia.camara.gov.br/. Acesso em 12 nov. 2015.
} 
2012). Fica, infelizmente, evidente que o título da dissertação foi alterada para o livro, mas o escopo da democracia conectada (ou digital) não foi, essencialmente, ampliado.

Certamente, a este ponto, o leitor já foi exposto a um grande conjunto de teorias, objetos e perspectivas, sem que haja, geralmente, uma conexão amarrada entre todas. Magrani conclui abordando a questão do engajamento online, suas conexões com os media massivos, com o jornalismo, com as sociedades contemporâneas, os movimentos sociais, ações coletivas efêmeras, democracia deliberativa, entre outros. Posteriormente, o autor vai admitir que se trata de uma seção sobre potenciais da rede para incremento da democracia numa visão otimista, mas, novamente, o autor não dialoga, interroga ou questiona estas teorias. Ademais, seguindo seu padrão, não há referências ou diálogos aos trabalhos nacionais sobre horizontalização da comunicação digital, sobre internet e política ou mesmo ciberativismo ${ }^{6}$, por mais que estes se tratem de temas com razoável produção na academia brasileira (SCHAUN et al., 2013).

Em seguida, o segundo capítulo ("Limites e desafios para uma democracia digital”) busca apresentar as visões críticas, céticas ou pessimistas a respeito da internet e das redes para contrabalancear a visão otimista apresentada anteriormente. Considero o capítulo melhor organizado e o mais interessante do livro. Em resumo, Magrani vai abordar a literatura internacional para tratar sobre 7 questões, problemas ou desafios principais, a saber: 1) exclusão digital; 2) sobrecarga de informação; 3) filtros-bolha; 4) polarização e fragmentação das discussões online; 5) falta de cultura política de engajamento; 6) excessiva tecnicização do debate; 7) uso das

\footnotetext{
${ }^{6}$ Por exemplo, boa parte destas questões acerca do ativismo online são apresentadas e discutidas por Maia (2007), Malini e Antoun (2013) e Silveira (2009).
} 
tecnologias para a vigilância e controle dos usuários. No geral, cada uma destas perspectivas é bem apresentada, bem ilustrada, complementada com casos e números e o leitor leigo tenderá a alcançar mais noção sobre cada tema após a leitura do capítulo. Porém, o problema é que autor não dialoga, questiona ou apresenta contrapropostas às críticas apresentadas pelos autores que apresenta. Cada um dos problemas é posto como algo insuperável e, praticamente, inerente às tecnologias digitais, tendendo assim a cristalizar os usos da miríade de ferramentas, plataformas, aplicativos existentes dentro do que chamamos de "internet". Friso, novamente, que não há diálogo com a literatura nacional. Vários autores nacionais já se preocuparam em apresentar as perspectivas positivas e céticas a respeito da internet, assim como o motivo deste debate já estar, em grande medida, superado (cf GOMES, 2005, 2011; MARQUES, 2010; SAMPAIO, 2010). A questão é que o leitor inexperiente nesses temas tenderá a acreditar que a visão levantada por Magrani não tem desafiantes ou alternativas.

Finalmente, o terceiro capítulo do livro busca analisar dois casos de e-democracia no Brasil, a saber o Marco Civil da Internet (como edemocracia institucional) e o fenômeno das jornadas de Junho de 2013 (como e-democracia não institucional). Notadamente, há uma disparidade gritante na apresentação dos dois casos, já que o Marco Civil da Internet (MCI) é brevemente discutido em 7 páginas, enquanto as jornadas de Junho recebem generosas 26 páginas. Exatamente por isso, a discussão sobre o MCI é rasa e mais ilustra o caso, que efetivamente o analisa. Há, basicamente, uma descrição de todo o seu processo, sem detalhes e sem dados que efetivamente embasem a visão do autor. Aqui, alguns autores da FGV são apresentados para caracterizar e dar soluções ao tema, mas não há, efetivamente, o diálogo mais amplo que questiono nesta resenha. 
Em seguida, faz-se, essencialmente, uma longa caracterização e descrição das jornadas de Junho de 2013, nas quais dados, conceitos e autores são utilizados sob a lógica de uma análise ampla do fenômeno. Todavia, na prática, a análise carece de mais metodologia, dados ou fontes que efetivamente pudessem comprovar sua visão. Como o texto provavelmente foi escrito pouco tempo depois das manifestações (pela data da publicação do livro), percebe-se que há uma ânsia em apresentar o fenômeno, mas não há, de fato, material teórico ou empírico para embasar uma análise mais robusta.

\section{Premissas problemáticas (ou a "promessa não cumprida da internet")}

No geral, mais que os problemas específicos acima elencados, há algumas suposições ou premissas problemáticas que permeiam todo o livro. Resumo-as abaixo.

"A" internet

Apesar de em diversos momentos reconhecer especificidades das plataformas, o livro tende a refletir sobre características gerais de "A" internet, como se esta fosse uma coisa única ou um bloco. Por beber de autores que fazem grandes generalizações, como Castells, Benkler, Hindman, Carr entre outros, o autor tende a apresentar características, potenciais e problemas gerais e intrínsecos "dA" internet. Enquanto vários usos e apropriações são citadas, estas teorias generalistas são pouco enfrentadas ao longo do livro, o que acaba contaminando o discurso e algumas análises realizadas em seu percurso. 
Mundo virtual x mundo real

Com base em Castells (2013), e referindo-se a formas contemporâneas de engajamento, Magrani reconhece que os jovens não tratam de

forma distintiva os espaço online e off-line. Ao contrário, tratam ambos como um continuum da experiência político-social, em um mundo conectado, percebido como uma experiência historicamente inédita que modifica significativamente as dinâmicas de engajamento tanto na esfera política quanto privada (p. 185).

Todavia, ao longo do livro, fica evidente que Magrani não só aceita tal separação entre o "mundo virtual" e o "mundo real" como realiza boa parte de suas análises com base na mesma. Como, por exemplo, quando está discutindo a questão do anonimato online $\mathrm{x}$ off-line e ressalta em nota de rodapé: "Novamente cabe aqui ressaltar que utilizamos o conceito de off-line para nos referirmos ao mundo físico não-virtual" (p. 181). Evidentemente, esta separação não apenas é falsa e artificial como, também, tende a separar fenômenos que já não podem vistos isoladamente, sob pena de serem simplificados ou compreendidos de maneira equivocada.

o que pode fazer a internet pela democracia?

Em diversos momentos, o autor menciona ou cita os "potenciais democráticos da internet" ou ainda as tais características gerais da internet que minam estes potenciais. Pelas apropriações dos usuários, resistências institucionais e falta de cultura política de 
participação, o autor também menciona os "potenciais perdidos" ou não aproveitados da internet para o incremento de valores democráticos. Em vários textos, Gomes $(2005,2010,2011)$ ressalta como a literatura de internet em política, em geral, e sobre democracia digital, em específico, começou questionando sobre "o que pode fazer a internet pela democracia" ou ainda sobre os potenciais democráticos da internet. Porém, tanto Gomes quanto a literatura sobre e-democracia (e.g. COLEMAN; BLUMLER, 2009; MARQUES, 2010; SAMPAIO, 2010; WRIGHT, 2012) já reconhecem que a fase de se refletir sobre os potenciais foi superada. 0 objetivo mais atual das reflexões é, geralmente, sobre a oferta, o design, os constrangimentos técnicos, burocráticos e políticos na oferta de tais ferramentas, de um lado, e as pesquisas que buscam verificar como se dá a apropriação dos cidadãos de tais ferramentas e iniciativas, do outro. Em ambos os casos, busca-se a compreensão de questões e fatores contextuais que podem ajudar a entender o "sucesso" ou não de iniciativas de democracia digital, sejam estas institucionais ou não. A abordagem sobre os potenciais da internet para a democracia tende a ser realizada sob um enquadramento revolucionário, que pode conduzir a, desnecessariamente, elevar os nossos padrões de avaliação e nos impedir de verificar mudanças menores (mas também significativas), como nos alerta Wright (2012).

\section{Conclusão}

Voltando à minha introdução, acredito que o livro "Democracia conectada: a Internet como Ferramenta de Engajamento PolíticoDemocrático" tem o mérito de apresentar um conjunto de conceitos e teorias relacionadas a temas diversos, como esfera pública, engajamento online, democracia digital, assim como perigos, 
problemas e limitações dos mesmos. Em especial, como há poucos livros autorais em português sobre o tema, particularmente, indico-o aos alunos leigos ou iniciantes no tema da democracia digital, assim como estes supracitados temas. Infelizmente, a obra tem pouco a acrescentar aos pesquisadores da área. Em especial, como ressaltei ao longo da resenha, chama-me a atenção como o autor faz uso de um grande número de autores em inglês, mas ignora a produção nacional. Decerto, é importante interagirmos e debatermos com a literatura de ponta em cada área. Não obstante, sendo um livro em português, voltado ao público brasileiro e provavelmente sendo atraente, especialmente, aos estudantes de graduação, parece-me um "potencial perdido" que o autor não tenha ampliado o debate à produção brasileira. Isso parece ocorrer com excessiva frequência nesta linha de internet e política.

Ainda assim, apenas a título de exemplo, a pesquisa de Nicolás, Bragatto e Sampaio (2013) evidencia que cerca de 300 artigos sobre internet e política foram apresentados no período de 2000 a $2011 \mathrm{em}$ eventos de Comunicação, Ciência Política e Sociologia. Se incluirmos áreas interessadas na temática da democracia digital, como Administração Pública, Gestão Pública, Direito e Ciência da Informação, assim como artigos publicados diretamente em revistas e livros (que não são considerados no escopo da pesquisa acima), fica evidente que há um número expressivo de artigos apresentados em eventos e publicados, seja no tema, seja em áreas afins. Ao se eximir de realizar este diálogo, creio que o livro apenas incorre em erros já superados pela literatura e acaba sendo menos capaz de contribuir para tais estudos no Brasil. 


\section{Referências}

ABREU, Júlio Cesar Andrade. Participação democrática na administração Pública mediada pela internet: o caso do orçamento participativo digital. 2012. Tese de Doutorado (Doutorado em Administração) - Programa de Pós-graduação em Administração, Universidade Federal da Bahia, Salvador, 2012.

AMORIM, Paula Karini. Democracia e Internet: a transparência de gestão nos portais eletrônicos das capitais brasileiras. Tese (Doutorado em Comunicação Social) - Programa de Pós-Graduação em Comunicação e Cultura Contemporâneas, Universidade Federal da Bahia, Salvador, 2012.

BENKLER, Yochai. The wealth of networks: How social production transforms markets and freedom. Yale University Press, 2006.

BEST, N.; RIBEIRO, M. M.; MATHEUS, R.; VAZ, J. Internet e a participação cidadã nas experiências de orçamento participativo digital no brasil. Cadernos PPG-AU/FAUFBA, v. 9, pp. 105-124, 2010.

BEZERRA, Heloisa Dias. Atores políticos, informação e democracia. Opinião Pública (UNICAMP. Impresso), v. 14, pp. 414, 2008.

BRAGA, Sérgio. Podem as novas tecnologias de informação e comunicação auxiliar na consolidação das democracias? Um estudo sobre a informatização dos órgãos legislativos na América do Sul. Opinião Pública (UNICAMP. Impresso), v. 13, pp. 1-50, 2007.

BRAGATTO, Rachel Callai. Democracia e internet: apontamentos para a sistematização dos estudos da área. Revista Compolítica, v. 1, n. 2, pp. 131-164, 2011.

CASTELLS, Manuel. A Sociedade em Rede - A Era da Informação: Economia, Sociedade e Cultura. Volume I. São Paulo: Paz e Terra, 1999.

CASTELLS, Manuel. Redes de indignação e esperança - movimentos sociais na era da Internet. Zahar, 2013.

CASTELLS, Manuel. Communication, power and counter-power in the network society. International Journal of Communication, v. 1, n. 1, p. 29, 2007.

COLEMAN, Stephen; BRUMLER, Jay G. The internet and democratic citizenship: theory, practice and policy. Cambridge: Cambridge University Press, 2009.

COSTA, Sergio. As cores de Ercilia: esfera pública, democracia, configurações pósnacionais. Belo Horizonte: Ed. UFMG, 2002.

CUNHA, M. A. V. C. A interação do vereador brasileiro com o cidadão e com o Poder Executivo por meios eletrônicos. In: CUNHA, Maria Alexandra; FREY, Klaus; DUARTE, Fábio. (Org.). Governança Local e as Tecnologias de Informação e Comunicação. Curitiba: Champagnat, 2009, v. 1, pp. 85-118.

DINIZ, Eduardo Henrique; RIBEIRO, Manuella M. O conceito de Esfera Pública Interconectada e o site Webcidadania no Brasil. Gestão \& Regionalidade, v. 29, pp. 97-111, 2012.

FARIA, Cristiano Ferri Soares. O parlamento aberto na era da internet: pode o povo colaborar com o Legislativo na elaboração das leis? Brasília: Câmara dos Deputados, Edições Câmara, 2012.

FERREIRA, Dimas Enéas Soares. Uma análise comparada do impacto dos usos das novas tecnologias digitais na dinâmica participativa e deliberativa dos orçamentos participativos de Belo Horizonte e Recife. Tese (Doutorado em Ciência Política), Universidade Federal de Minas Gerais, Belo Horizonte, 2012. 
GOMES, Wilson. Participação Política Online: Questões e hipóteses de trabalho. In: MAIA, R. C. M.; GOMES, W.; MARQUES, F. P. J. A. Internet e Participação política no Brasil. Porto Alegre: Sulina, 2011, pp. 19-45.

A democracia digital e o problema da participação civil na decisão política. Revista Fronteiras: estudos midiáticos, v.7, n. 3, pp. 214-222, setembro/dezembro 2005.

. Democracia digital: Que democracia?. In: MIGUEL, Luís Felipe; BIROLI, Flávia. (Org.). Mídia, representação e democracia. São Paulo: Hucitec, 2010, pp. 241-259.

GOMES, Wilson; MAIA, Rousiley C.M. Comunicação \& democracia: Problemas e perspectivas. São Paulo: Paulus, 2008.

HABERMAS, Jürgen. Comunicação política na sociedade mediática: o impacto da teoria normativa na pesquisa empírica. Líbero, v. 11, n. 21, pp. 9-22, 2008.

MAIA, Rousiley Celi Moreira. Redes cívicas e internet: efeitos democráticos do associativismo. Logos, Rio de Janeiro, vol. 14, pp. 43-62, 2007.

. Deliberation, the media and political talk. Hampton Press, 2012.

MALINI, Fabio; ANTOUN, H. A internet e a rua: ciberativismo e mobilização nas redes sociais. 1. ed. Porto Alegre: Editora Sulina, 2013.

MARQUES, Francisco Paulo Jamil Almeida. Muro baixo, o povo pula: iniciativas institucionais de participação digital e seus desafios fundamentais. Opinião Pública, v. 16, pp. $117-142,2010$

NICOLAS, M. A.; BRAGATTO, R. C.; SAMPAIO, R. C. Internet and Politics studies in Brazil: mapping the characteristics and disparities of the research field. Brazilian Political Science Review, v. 7, pp. 114-140, 2013.

PARKINSON, John; MANSBRIDGE, Jane (Orgs.). Deliberative Systems: Deliberative Democracy at the Large Scale. New York: Cambridge University Press, 2012.

PRADO, Otavio. Governo eletrônico e transparência: a publicização das contas públicas das capitais brasileiras. 2004. Dissertação (Mestrado em Administração). Fundação Getulio Vargas, São Paulo, 2004.

SAMPAIO, Rafael Cardoso. Participação e Deliberação na internet: um estudo de caso do Orçamento Participativo Digital de Belo Horizonte. 2010. 191 f. Dissertação (Mestrado em Comunicação Social). Programa de Pós-Graduação em Comunicação Social, Universidade Federal de Minas Gerais, Belo Horizonte, 2010.

STEINER, Jürg. The foundations of deliberative democracy: Empirical research and normative implications. Cambridge: Cambridge University Press, 2012.

ROSSETTO, G. P. N.; CARREIRO, R. Democracia digital e sociedade civil: uma perspectiva do estado atual no Brasil. Comunicação e Sociedade, v. 34, n. 57, 2012.

SILVA, Sivaldo Pereira. Graus de participação democrática no uso da Internet pelos governos das capitais brasileiras. Opinião Pública, v. 11, pp. 450-468, 2005.

SILVEIRA, Sergio Amadeu. Esfera Pública Interconetada, blogosfera e redes sociais. In: MARQUES, Ângela; COSTA, Caio Túlio; KÜNSCH, Dima et al (Orgs.). Esfera pública, redes e jornalismo. Rio de Janeiro, E-Papers, 2009, pp. 9-30.

ROTHBERG, Danilo. Por uma agenda de pesquisa em democracia eletrônica. Opinião Pública, v. 14, n. 1, pp. 149-172, 2008. 
SAMPAIO

PENTEADO, Cláudio. L. C. ; SANTOS, Marcelo Burgos P.; ARAUJO, Rafael P. A. ; SILVA, S. J. Ação política na Internet Brasileira. Perspectivas em Ciência da Informação (Online), v. 16, pp. 111-132, 2011.

PINHO, J. A. G. Investigando portais do governo eletrônico de estados no Brasil: muita tecnologia, pouca democracia. Revista de Administração Pública, V. 42, N.3, pp.471-93, 2008.

SCHAUN, Angela et al. (2013). Brazilian Scientific Production on Cyberactivism in the Communication area from 2002 to 2012: a preliminary mapping". Journal of Latin American Communication Research, v. 3, n. 1, pp. 36-56.

WRIGHT, Scott. Politics as usual? Revolution, normalization and a new agenda for online deliberation. New Media \& Society, v. 14, n. 2, p.244-261, 2012.

COMPOLITTICA

ASSOCIACEÃO BRASILEIRA

DE PESQUISADORES EM

COMUNICACÁO E POLITITICA

Diretoria da Associação/ Director Boara

Presidente | President

Fernando Lattman-Weltman (UERJ)

Vice-Presidente | Vice-President

Arthur Ituassu (PUC-Rio)

Secretária Executiva | Executive Secretary

Kelly Prudêncio (UFPR)

Corpo Editorial / Editorial Board

Coordenação Editorial | Editorial Coordination Alessandra Aldé (UERJ) \& Maria Helena Weber (UFRGS)

Editores Executivos | Executive Editors Camilo Aggio (UFBA), Diógenes Lycarião (UFC), Rafael Cardoso Sampaio (UFPR) \& Viktor Chagas (UFF)
A Revista Compolítica é uma revista eletrônica da Associação Brasileira de Pesquisadores em Comunicação e Política

[Revista Compolitica is an electronic journal published by the Brazilian Association of Political Communication Scholars]

Ao citar este artigo, utilize a seguinte referência bibliográfica

[To cite this article, please use the following reference]

SAMPAIO, Rafael Cardoso. Democracia desconectada: da necessidade do diálogo com a literatura nacional. In: Revista Compolítica 5 (2), 2015. 
